\title{
Inter-rater Assessment on Listening Media for Foreign Language Speakers
}

\author{
Memet Sudaryanto ${ }^{1}$, Chafit Ulya ${ }^{2}$, Muhamad Rohmadi ${ }^{3}$, Kuhafeesah ${ }^{4}$ \\ ${ }^{1234}$ Sebelas Maret University, Indonesia \\ ${ }^{1}$ memetsudaryanto@staff.uns.ac.id ${ }^{2}$ chafit@staff.uns.ac.id \\ 3mamad r76@staff.uns.ac.id
}

\begin{abstract}
Listening skills become complex if delivered with inappropriate media especially for foreign speakers. This research is to (1) describe the process of media development based on the work of foreign speakers, and (2) inter-rater test to describe the reliability of the speaking product and the results of the assessment on the learning media developed. Research methods for developing learning media and speaking competency assessment through a mix method which is a combination of qualitative and quantitative research. A qualitative approach to the development of speaking material that is transformed into a medium of listening skills. Quantitative approach is carried out in the process of speaking skills assessment and inter-rater assessment on listening skills media in accordance with criteria that are arranged qualitatively. Reliability evaluation of the media shows that each expert agrees on the quality of the media. The media developed for listening learning can work best with the help of recorded podcasts on speaking learning. Synchronous speaking and writing skills as a starting capital for understanding listening skills is increasingly urgent with a self-need approach in accordance with goals and needs. This shows that the media can be made as authentic as possible according to class conditions, number of foreign speakers, local culture, time, and location around the class.
\end{abstract}

Keywords: Foreign, Language, Inter-rater, Listening

\section{PENDAHULUAN}

Media pembelajaran merupakan alat yang digunakan untuk mempermudah penyampaian materi. Media memiliki ragam yang berbeda-beda dengan kualifikasinya berdasar pada kebutuhan dan kondisi mahasiswa penutur asing. Dalam konteks pembelajar bahasa kedua, media pembelajaran merupakan salah satu faktor yang bisa menyukseskan pencapaian indikator belajar yang direncanakan oleh pengajar BIPA (Bahasa Indonesia bagi Penutur Asing) [1]. Secara praktis, media pembelajaran yang bisa digunakan sudah ditentukan sebelumnya di saat yang sama pengajar menentukan indikator yang akan dicapai.

Karakteristik dari pembelajaran bahasa merupakan integrasi dari kognitif, psikomotor, dan afektif yang harus dikuasai oleh mahasiswa penutur asing dengan tujuan pembelajaran apapun [2]. Penguasaan bahasa yang baik didukung oleh pemahaman pada konteks tuturan, penyampaian gagasan, dan penerimaan bahasa tersebut [3]. Perumusan indikator pencapaian kompetensi berbahasa disusun berdasarkan penguasaan keterampilan menyimak, berbicara, membaca, dan menulis. Masing-masing keterampilan tersebut diajarkan degan metode dan 
pendekatan yang berbeda, yakni sesuai dengan karakteristik materi dan pemahaman mahasiswa penutur asing.

Pembelajaran bahasa Indonesia bagi penutur asing mengalami kendala teknis utamanya pada kemampuan menyimak dan berbicara [4]. Berbeda dengan konteks materi yang disusun sistematis oleh pengajar BIPA, mahasiswa penutur asing menguasai bahasa Indonesia berdasarkan kolaborasi adaptif dengan bahasa pertama yang diperoleh sebelum belajar di Indonesia. Kelebihan yang bisa ditemukan adalah makin mirip bahasa asal dengan bahasa Indonesia yang dipelajari di kelas, maka penguasaan bahasa pun akan makin cepat dan lebih akurat terutama dengan tujuan pembelajaran dan komunikasi [5].

Karakteristik bahasa Indonesia yang beragam dan unik membutuhkan perhatian ekstra bagi mahasiswa penutur asing untuk menemukan sintaks kebahasaan yang harus dipahami dan diterapkan dalam kehidupan sehari-hari. Mahasiswa penutur asing yang menemukan metode belajar bahasa yang lebih cepat karena pola kebahasaan yang dilakukan secara kontinu dan berkelanjutan melalui pelatihan mandiri di luar kelas [6]. Interaksi yang dilakukan mahasiswa penutur asing di luar kelas membentuk kemandirian belajar yang lebih baik. Mahasiswa penutur asing mampu melakukan penilaian sendiri pada saat melakukan kesalahan tuturan serta memperbaikinya sekali waktu.

Proses belajar aktif yang dilakukan mahasiswa penutur asing di luar kelas merupakan blinded process yang indikator pencapaiannya kontras dengan proses di dalam kelasa. Hal tersebut dikarenakan bahasa Indonesia memiliki ragam yang bervarian, yakni percakapan untuk tujuan akademik dan komunikasi. Secara subjektif, media pembelajaran merupakan alat yang bisa mempermudah proses belajar meskipun di lain sisi subjektivitas masyarakat pengguna lain berpendapat berbeda [7].

Pengembangan media pembelajaran bagi penutur asing bisa dibuat sesuai dengan kebutuhan penggunanya maupun pembuatnya. Hal tersebut menunjukkan bahwa media bisa dibuat seautentik mungkin sesuai dengan keadaan kelas, jumlah penutur asing, budaya setempat, waktu, dan lokasi sekeliling kelas. Relevan dengan pernyataan di atas, media pembelajaaran yang baik untuk proses menyimak merupakan media yang dikembangkan dari keterampilan berbahasa lain yakni proses berbicara, membaca, dan menulis.

Keterampilan menyimak merupakan kunci dalam penerimaan pesan secara efektif. Keterampilan ini adalah kombinasi dari menyimak yang dikatakan orang lain dan keterlibatan secara psikologis dalam konteks yang didengarkan. [8] Menyimak sebagai keterampilan berbahasa membutuhkan motivasi untuk mengerti pesan yang disampaikan oleh mitra tutur. Sikap yang ditunjukkan berupa penerimaan dan kemauan untuk membuka pikiran serta mencoba melihat sesuatu dari sudut pandang orang lain. Keterampilan menyimak membutuhkan konsentrasi tinggi tingkat. Hal tersebut menuntut penyimak mengesampingkan pikiran dan menempatkan diri pada posisi orang lain dan mencoba melihat dunia melalui itu mata orang lain.

Proses menyimak menjadi kompleks bergantung pada pesan dan media yang digunakan untuk menyampaikan pesan tersebut. Pesan sederhana yang disampaikan dengan media yang tidak tepat dapat menyulitkan penerimaan pesan tersebut. Di samping itu, pesan yang kompleks dan disampaikan dengan media yang tepat akan diterima dengan mudah. Secara empiris, pembelajaran bahasa Indonesia bagi penutur asing mengalami kendala pada kemampuan menyimak dan berbicara agar bersinergi untuk meningkatkan kemampuan dalam berkomunikasi secara akademik.

Tiga alasan mengapa menyimak tidak diajarkan dengan baik. Pertama-tama, mendengarkan tidak diterima sebagai keterampilan terpisah untuk diajarkan secara eksplisit untuk waktu yang lama. Pembelajar bahasa akan meningkatkan keterampilan menyimak 
mereka sendiri saat mereka menyimak pada konteks-konteks pembelajaran di luar kelas. Kedua, para pengajar merasa tidak menguasai kompetensi untuk mengajarkan keterampilan mendengarkan. Selain itu, materi ajar menyimak terlalu konvensional untuk pengajaran bahasa sehingga materi tidak cukup efisien untuk mengajar keterampilan menyimak. Memahami makna bahasa yang diucapkan bagi pembelajar bahasa membutuhkan lebih banyak upaya ketika dibandingkan dengan penutur asli bahasa Indonesia. Misalnya, perbedaan kebisingan dan pelesapan atau pelafalan di luar bentuk fonemis bahasa asal yang akan memengaruhi penerimaan pada penutur asing.

\section{METODE PENELITIAN}

Penelitian ini merupakan mix method penelitian kualitatif dan kuantitatif untuk menemukan solusi paling efektif dalam menemukan kesahihan data yang ditunjukkan dengan keruntutan alur dan pencapaian kesepakatan antarrater dalam melihat efektivitas produk yang dihasilkan [9]. Secara kualitatif, data yang dianalisis berupa hasil tulisan penutur asing mengenai topik-topik yang relevan dengan kehidupan di Indonesia. Data yang dianalisis konten merupakan kesesuaian topik dan keruntutan ide pokok antarparagraf berdasarkan kriteria tulisan dan tata bahasa Indonesia. Indikator disusun berdasarkan perumusan konstruk menulis dalam bahasa Indonesia. Studi kuantitatif dalam penelitian ini adalah analisis skor pada (1) hasil keterampilan menulis penutur asing, (2) pengujian validitas isi, (3) estimasi reliabilitas, dan (4) pengukuran kemampuan penutur asing. Masing-masing estimasi dideskripsikan untuk menunjukkan bahwa data dapat disimpulkan untuk menjawab rumusan masalah. Proses pengambilan simpulan dilakukan secara bertahap secara kuantitatif dan kualitatif [10].

\section{HASIL DAN PEMBAHASAN}

Keterampilan berbahasa merupakan bentuk kompleksitas keterampilan yang dikuasai secara langsung oleh setiap penutur bahasa. Salah satu keterampilan dasar paling wajib dikuasai adalah keterampilan menyimak karena sebagai dasar penguasaan keterampilan lainnya. Erat hubungan antara keterampilan menyimak dan berbicara perlu diintegrasikan dalam media pembelajaran yang mendukung proses pembelajaran pada penutur bahasa agar makin mahir terutama bagi penutur asing.

\subsection{Analisis Kebutuhan}

Untuk pembelajar bahasa, sulit untuk membuat prediksi terutama jika penutur asing tidak terbiasa dengan idiom, peribahasa dan kolokasi yang umum digunakan pada bahasa Indonesia. Berbagai fitur bahasa lisan dalam bahasa indonesia seperti penekanan dan intonasi memiliki peran penting untuk dikuasai pada situasi tertentu. Selain itu, mencoba menafsirkan leksis dan bunyi yang asing untuk waktu yang lama sangat melelahkan bagi sebagian besar penutur asing. Aksen berbeda yang mereka hadapi juga bisa menjadi masalah bagi banyak pelajar bahasa karena terutama dalam konteks bahasa Indonesia sedangkan penutur asing terbiasa mendengar L2 dari pengajar selama ini yang berbicara bahasa Indonesia sebagai bahasa asing. Namun, bahasa Indonesia digunakan di berbagai ragam komunikasi dan penutur asing perlu diberi kesempatan untuk membiasakan diri dengan aksen yang berbeda yang dapat membantu dalam mengatasi masalah ini.

Beberapa masalah yang dialami penutur asing dalam berbahasa Indonesia terutama pada materi keterampilan menyimak antara lain. 


\begin{tabular}{ll}
\hline Perception & Secara harfiah memahami kata-kata yang diketahui saja \\
& Mengabaikan bagian selanjutnya ketika memahami makna dalam satu konteks \\
& Tidak memahami pemenggalan dalam percapakan \\
& Kehilangan awal teks (pembuka) sehingga memecah konsentrasi \\
& Berkonsentrasi terlalu keras atau tidak dapat berkonsentrasi \\
\hline Parsing & Cepat dalam melupakan yang didengar \\
& Tidak dapat membentuk representasi mental dari kata-kata yang didengar \\
& Terlalu memahami bagian awal selanjutnya karena masalah sebelumnya \\
\hline Utilization & Memahami kata-kata (diksi) yang dipilih tetapi bukan pesan yang dimaksud \\
& Bingung menentukan ide-ide utama dalam pesan yang disimak \\
\hline
\end{tabular}

Berdasarkan permasalahan yang dialami penutur asing, dirumuskan (1) tugas menulis mengenai laporan hasil observasi, (2) membacakan dan mempresentasikan laporan hasil observasi, (3) melakukan rekaman sebagai konversi media tulis menjadi media audio, dan (4) melakukan penilaian atas kualitas dan konten media berbicara yang dinilai oleh expert di bidang keterampilan berbahasa. Langkah tersebut ditempuh untuk menghasilkan produk media keterampilan berbicara yang sesuai dengan indikator dan kriteria media yang efektif untuk pembelajaran bagi penutur asing.

\subsection{Media Menyimak}

Laporan hasil obervasi yang dihasilkan oleh penutur asing membutuhkan proses yang panjang. Beberapa tahapan dalam menghasilkan tulisan berkualitas, yakni (1) perencanaan: pemilihan topik tulisan, praobservasi, mencatat bagian penting yang diobservasi dan mengambil gambar/dokumentasi proses (2) pengembangan kerangka tulisan: observasi dengan kerangka, mengembangkan kerangka tulisan, (3) merevisi tulisan: setiap penutur asing melakukan koreksi atas tulisan teman penutur asing lainnya sesuai dengan media menyimak yang mau dikembangkan, (4) merevisi konten dan tata tulis kebahasaan agar mudah terbaca.

Penutur asing melakukan rekaman dengan memperhatikan artikulasi, intonasi, jeda, dan nada suara yang tepat sesuai konteks yang dibangun [11]. Rekaman yang dihasilkan diberikan stimulus tambahan berupa backsound yang mendukung proses penerimaan informasi. Penutur asing diberikan stimulus untuk menyimak penutur asli bahasa Indonesia dalam bercakap dan membiasakan untuk beradaptasi terhadap intonasi yang dilafalkan oleh penutur asli Indonesia di konteks secara umum.

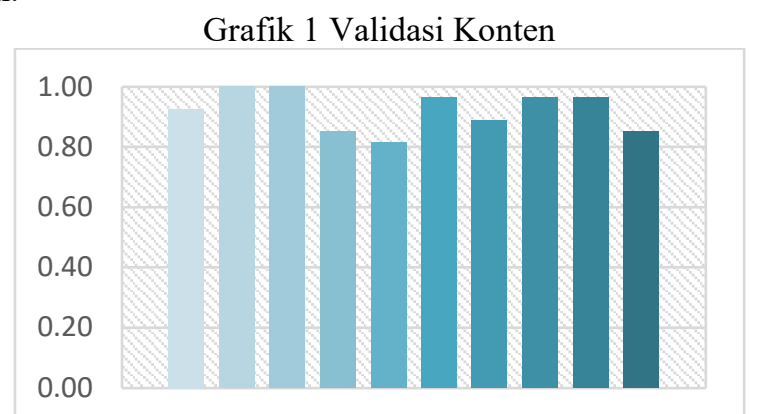

Berdasarkan validasi oleh expert mengenai (1) kesesuaian tema dengan hasil kerja penutur asing: penutur asing mengembangkan tema yang sesuai projek yang telah ditugaskan, (2) kesesuaian dan bentuk wacana: mahasiswa menentukan wacana sesuai dengan bentuk teks yang mau ditampilkan, (3) kesesuaian wacana dengan indikator: indikator yang mau dicapai oleh penutur asing adalah kemampuan beradaptasi di Indonesia dan kemampuan 
menyammpaikan gagasan dengan cara paling mudah diterima, dan (4) keluasan wacana dan pengembangan topik: makin luas topik yang dikuasai oleh penutur asing maka menunjukkan makin luas komunikasi yang bisa dikuasai.

\subsection{G-Theory Keterampilan Berbicara}

Berdasar pada desain yang diajukan untuk penilaian media menyimak tentunya desain generalisabilitas (G-Design) yang digunakan adalah desain bersilang (cross design), karena masing-masing penutur asing (p) menjadi subjek yang diamati tiga orang pengamat/rater yang merupakan ahli di masing-masing bidang yang telah ditentukan (o) yang keduanya menilai empat aspek pengamatan/indikator (i). Dengan demikian, desain generalisabilitas yang digunakan adalah p x i x r [12].

Berdasarkan konstruksi yang disusun pada gambaran di atas, desain generalisabilitas dengan model 2 facet, yaitu facet aspek penilaian/indikator (i), dan faset pengamat/observer (o). Adapun mahasiswa, dalam hal ini berlaku sebagai subjek pengamatan, bukan sebagai facet, karena bukan merupakan sumber kesalahan dalam pengamatan. Selanjutnya, yang menjadi uviverse of admissible observation adalah 25 mahasiswa yang dijadikan subjek pengamatan sebagai sampel, dari sejumlah populasi mahasiswa asing yang tinggal di Indonesia menjadi tempat generalisasi (universe of generalization). Hasil pengamatan dan penilaian dari dua penilai kemudian dianalisis dengan excel, atau dapat juga dengan SPSS dengan analisis varians tiga jalur.

Dari hasil analisis varians yang dilakukan, didapatkan nilai mean square masingmasing faset seperti yang tertera pada tabel di bawah. Selanjutnya, hasil mean square tiap faset kemudian digunakan untuk mencari varians tiap faset pada pengukuran ini. Berdasarkan perhitungan dengan rumus yang ada, maka memungkinkan menghasilkan estimasi komponen varian yang bernilai negatif [13]. Meskipun secara definitif komponen varian tidak bisa negatif, [14]. Untuk penghitungan estimasi pada komponen yang hasilnya negatif, bisa digantikan dengan nol (0).

Tabel.1

ANOVA for $\mathrm{p} \times \mathrm{i} \times$ o Design Using Synthetic Data Set No. $3^{*}$ with $\mathrm{np}=25 \quad \mathrm{ni}=4 \quad \mathrm{no}=2$

\begin{tabular}{lccrrrr}
\hline \multicolumn{1}{c}{ Effect $(\alpha)$} & $\mathrm{df}(\alpha)$ & $\mathrm{f}(\alpha)$ & \multicolumn{1}{c}{$\mathrm{T}(\alpha)$} & \multicolumn{1}{c}{$\mathrm{SS}(\alpha)$} & \multicolumn{1}{c}{$\mathrm{MS}(\alpha)$} & \multicolumn{1}{c}{$\sigma^{\wedge} 2(\alpha)$} \\
\hline $\mathrm{p}$ & 24 & 8 & 10040,13 & 113,72 & 4,7383 & 0,3414 \\
\hline $\mathrm{i}$ & 3 & 50 & 9927,14 & 0,74 & 0,2450 & $-0,0382$ \\
\hline $\mathrm{o}$ & 1 & 100 & 9941,53 & 15,13 & 15,1250 & 0,3038 \\
\hline pi & 72 & 2 & 10073,50 & 32,64 & 0,4533 & $-0,2047$ \\
\hline po & 24 & 4 & 10113,25 & 58,00 & 2,4167 & 0,3885 \\
\hline io & 3 & 25 & 9946,52 & 4,26 & 1,4183 & 0,0556 \\
\hline pio & 72 & 1 & 10213,00 & 62,12 & 0,8628 & 0,8628 \\
\hline Mean $(\mu)$ & & 80 & 9926,41 & & & \\
\hline Total & 199 & & & 286,60 & & \\
\hline
\end{tabular}

Berdasarkan pada hasil skor yang diamati di table di atas nilai observe score berkisar antara 0 sampai 9. Nilai dari $\sigma^{(}(p)$ merupakan yang tertinggi dibandingkan dengan nilai estimasi variance component means score item dan occasion Nilai dari $\sigma^{\gamma}(p)$ dipengaruhi oleh kesamaan pada skor rata-rata occasion yang diamati. Nilai $\sigma^{\gamma}(p i)$ lebih besar daripada $\sigma^{\gamma}(p o)$ 
dan $\sigma^{\text {(io }}$ ) yang menyarankan bahwa interaksi item-person adalah penting dan perlu diperhatikan saat mendesain sebuah prosedur

\section{SIMPULAN}

Media menyimak dikembangkan berdasarkan hasil pembelajaran pada keterampilan berbicara. Penutur asing melakukan rekaman dengan memperhatikan artikulasi, intonasi, jeda, dan nada suara yang tepat sesuai konteks yang dikenali agar mempermudah proses belajar. Pembelajaran untuk penutur asing akan dibuat lebih bermakna dengan menghasilkan produk media keterampilan berbicara yang sesuai dengan indikator dan kriteria media yang efektif untuk pembelajaran bagi penutur asing. Berdasarkan hasil analisis kebutuhan penting untuk dianalisis media-media menyimak yang bisa membantu memperlancar proses belajar berbahasa Indonesia. Berdasarkan hasil analisis validasi isi dan review expert menunjukkan kesesuaian tema dengan hasil kerja penutur asing, kesesuaian dan bentuk wacana, kesesuaian wacana dengan indikator, dan keluasan wacana dan pengembangan topik. Berdasarkan hasil analisis varian dengan teori-G menunjukkan bahwa expert mengambil simpulan bahwa media yang dihasilkan oleh penutur asing sebagai hasil belajar keterampilan berbicara untuk keterampilan menyimak cukup memadai untuk diimplementasikan di kelas.

\section{REFERENCES}

[1] M. Sudaryanto et al., "Indonesian as a Foreign Language: Standard Setting and Materials Development Issues," in 1st Workshop on Environmental Science, Society, and Technology, WESTECH, 2019, pp. 178-184.

[2] K. Saddhono, "Integrating culture in Indonesian language learning for foreign speakers at Indonesian universities," J. Lang. Lit., 2015.

[3] K. D. Kinzler, E. Dupoux, and E. S. Spelke, "'Native' Objects and Collaborators: Infants' Object Choices and Acts of Giving Reflect Favor for Native Over Foreign Speakers," J. Cogn. Dev., 2012.

[4] M. M. Zyoud, "Theoretical Perspective on How To Develop Speaking Skill," An Int. Multidiscip. J., 2016.

[5] B. B. Khleif, "Cultural regeneration and the school: An anthropological study of Welsh-medium schools in Wales," Int. Rev. Educ., 1976.

[6] P. K. Kuhl, F. M. Tsao, and H. M. Liu, "Foreign-language experience in infancy: Effects of short-term exposure and social interaction on phonetic learning," Proc. Natl. Acad. Sci. U. S. A., 2003.

[7] R. E. Mayer, "Using multimedia for e-learning," Journal of Computer Assisted Learning. 2017.

[8] M. Sudaryanto, D. Mardapi, and S. Hadi, "How foreign speakers implement their strategies to listen indonesian language?," J. Adv. Res. Dyn. Control Syst., 2019.

[9] R. Thomas, Blending Qualitative \& Quantitative Research Methods in Theses and Dissertations. 2011.

[10] R. de Beaugrande, "Critical discourse analysis: History, ideology, methodology," Stud. Lang. Capital., 2006.

[11] Anita Dighe, Understanding Our Learners, no. March. 2003.

[12] R. M. Furr, Scale Construction and Psychometrics for Social and Personality Psychology. 2014.

[13] G. E. Matt and M. Sklar, "Generalizability Theory," in International Encyclopedia of the Social \& Behavioral Sciences: Second Edition, 2015. 
[14] R. L. Brennan, "Generalizability theory," in International Encyclopedia of Education, 2010. 